\title{
О РАЗВИТИИ ТУРИСТСКО-ГОСТИНИЧНОГО БИЗНЕСА В ИРКУТСКОЙ ОБЛАСТИ
}

\begin{abstract}
АНнотАЦия. В статье прослеживается динамика развития гостинично-туристской сферы в Иркутской области, отражая и советский период и современные тенденции. Автор отмечает, что в ближайшие годы вырастет спрос на отдых в малонаселенных местах, сохранивших природную первозданность и при этом несущих отпечаток различных этнических культур. Подчеркиваются основные тенденции развития предпринимательства в гостиничном бизнесе региона, к которым относится активное развитие как крупных, так и малых гостиниц, это связано с предпочтениями современных туристов: одни хотят ощутить домашний уют, уникальность и неповторимость, что как раз является одной из отличительных черт малых независимых гостиниц, другие любят обслуживание по мировым стандартам с большим перечнем дополнительных услуг и развитой инфраструктурой. Через показатели загрузки, уровня заработной платы и среднегодовой численности работающих в гостиничной сфере, автор делает выводы о современном состоянии и перспективах развития гостиничной отрасли, акцентируя внимание на главных проблемах и методах их преодоления.
\end{abstract}

кЛЮчЕВЫЕ словА. Турагент; туроператор; турпродукт; гостиничный бизнес; загрузка отеля; туристский поток.

ИНФОРМАЦИЯ О СТАТЬЕ. Дата поступления 27 апреля 2017 г.; дата принятия к печати 13 марта 2017 г.; дата онлайн-размещения 31 марта 2017 г.

\section{E. A. Rzhepka \\ Baikal State University, Irkutsk, Russian Federation}

\section{ON DEVELOPING TOURISM AND HOTEL BUSINESS IN IRKUTSK OBLAST}

\begin{abstract}
The article aces dynamics of the hotel and tourism sphere in Irkutsk Oblast while reflecting both the Soviet period and the modern trends. The author notes that the coming years will see an increasing demand for rest in scarcely populated areas that have preserved their natural primevalness while bearing an imprint of various ethnical cultures. The article stresses the major trends of developing entrepreneurship in the region's hotel business including active development of both big and small hotels e, which is connected with preferences of today's tourists: some want to feel a homely home, the uniqueness and singularity that is exactly one of the hallmarks of small independent hotels, while the others like services according to the world standards with a large list of additional services and developed infrastructure. Using the indicators of the hotel intensity, the level of salaries and average annual number of those working in the hotel sphere, the author draws the conclusions of the current state and development prospects for the hotel sector stressing her attention on the main problems and methods of their coping with.
\end{abstract}

KEYWORDS. Travel agent; tour operator; tourist product; hotel business; tourist flow. ARTICLE INFO. Received April 27, 2017; accepted March 13, 2017; available online March 31, 2017.

Природные условия и ресурсы являются основой формирования туристских территорий. В глобальной популярности туристских объектов озера являются вторыми после морских побережий [1-3].

(C) Э. А. Ржепка, 2017

\section{Baikal Research Journal}


Байкальский регион известен в России и за рубежом своими уникальными туристскими ресурсами. На его территории находится озеро Байкал - самое глубокое озеро в мире, воды которого отвечают качествам питьевой воды. В нем обитает более 2 тыс. видов растений и животных, $2 / 3$ из них являются эндемиками [4]. Благодаря своим удивительным свойствам озеро Байкал, первым из природных объектов России, занесено в список всемирного наследия ЮНЕСКО [5]. Особую привлекательность природе Прибайкалья придают ненарушенные естественные ландшафты, природа щедро наградила территорию Иркутской области лечебно-минеральными ресурсами. Здесь расположен самый мощный в мире Ангаро-Ленский артезианский бассейн минеральных вод $\left(2700\right.$ км$\left.^{3}\right)$, на территории области сосредоточено около 300 минеральных источников, 6 крупных лечебных грязевых озер [6].

Развитие туризма в Иркутской области идет достаточно быстрыми темпами, а до начала 90-х гг. прошлого века только три крупнейших компании обеспечивали въездной и выездной туризм. Это ВАО «Интурист», по линии которого в Иркутскую область регулярно приезжали группы российских и иностранных туристов останавливающиеся в нашем городе на 1-3 дня, а наши земляки в составе групп путешествовали в основном по странам Европы, БММТ «Спутник» предоставлял возможность путешествовать не только по экскурсионным программам, но и по активным, событийным и другим видам туров, а Областной совет профсоюзов закрывал оздоровительную нишу путешествий [7].

В 1995 г. впервые в администрации Иркутской области была создана отдельная структура, курирующая туристскую отрасль - это отдел туризма. Именно этот факт и можно считать точкой начала активного развития туризма [2].

Уже к 1998 г. количество туркомпаний возросло до 49 (по сравнению с 15 компаниями в 1995 г.) среди них в основном были небольшие фирмы с количеством работников от 3 до 5 чел. В это же время стало начинаться деление турфирм на турагенства и туроператоров и к началу 2000 -х гг. уже 26 компаний специализировались на въездном туризме, 25 - на выездных турах и 37 компаний работали и на отправку, и на прием.

Так как позволить себе путешествие уже могло достаточно большое количество иркутян, то рост туркомпаний пошел в геометрической прогрессии (ежегодно увеличиваясь на 5-10 фирм по каждому направлению). В 2008 г. в области работало 103 туроператора и 150 турагента, казалось бы это предел, но по данным 2015 г. уже 245 турагентов и 86 туроператоров осуществляли свою деятельность в области.

Глядя на то, что численность туроператоров немного уменьшилась понимаешь, что наши компании предпочли продавать турпродукт уже созданный и достаточно отработанный крупными московскими фирмами. Начиная с 2008 г. на наш рынок активно вошли такие мощные международные туроператоры как «Пегас туристик» и «Тез тур», немного позже, а 2011 г. к ним присоединились «Корал тревел», «Анекс тур». В ближайшее время эта тенденция сохранится, и наши международные туроператоры просто не смогут конкурировать по выезду с этими компаниями.

Что касается процесса въезда туристов в наш регион, то по данным статистики, этот процесс неуклонно расширяется и географически, и численно. Перспективы развития туристической отрасли в области огромны. В ближайшие годы вырастет спрос на отдых в малонаселенных местах, сохранивших природную первозданность и при этом несущих отпечаток различных этнических культур. Социологи объясняют это тем, что люди устают от цивилизации, от урбанистического образа жизни, от бизнеса, поэтому все отчетливее проявляется их склонность к «настоящему вечному» - природе и культуре [8].

\section{Baikal Research Journal}

электронный научный журнал Байкальского государственного университета 
И если туристских компаний оказалось более, чем достаточно для обслуживания, то гостиничный рынок имеет резервы для роста.

К основным тенденциям развития предпринимательства в гостиничном бизнесе региона относится активное развитие как крупных, так и малых гостиниц, это связано с предпочтениями современных туристов: одни хотят ощутить домашний уют, уникальность и неповторимость, что как раз является одной из отличительных черт малых независимых гостиниц, другие любят обслуживание по мировым стандартам с большим перечнем дополнительных услуг и развитой инфраструктурой [9]. Объем ввода гостиниц ежегодно прирастает в целом по стране на $50 \%$. Сегодня малые отели зачастую занимают самые ликвидные участки в центре городов, причем без инвестиций в приобретение земли и строительство новых зданий [10]. Отмечаются сравнительно небольшие капиталовложения при строительстве малых гостиниц и более быструю окупаемость. Срок окупаемости для малых гостиниц примерно 5-6 лет, а для крупных 8-10 лет. Негативным фактором остается то, что уровень сервиса в таких заведениях очень отличается друг от друга [11].

Необходимо отметить тенденцию современных инвесторов вкладывать средства в строительство отелей высокой категории, которые окупаются намного быстрее, чем двух-, трехзвездные гостиницы, приносящие прибыль только через 8-10 лет после открытия [12;13].

Основные проблемы развития гостиничного комплекса в Иркутской области можно объединить в группы:

1. Недостаточно удовлетворительное состояние гостиничной инфраструктуры, что стало важнейшим негативным и сдерживающим развитие туризма фактором. Сегодня в регионе преобладают гостиницы старого советского образца - порядка $52 \%$, в то время как полностью реконструированных отелей не более $15 \%$. Многие средства размещения требуют обновления. Преодолеть сложившуюся ситуацию можно только путем серьезных инвестиционных вложений в гостиничную индустрию (реконструкция $1 \mathrm{~m}^{2}$ гостиничного номера «под ключ» в среднем обходится в 250 дол., на 1 м² $^{2}$ ресторана уйдет вдвое больше -500 дол.).

2. Отсутствие большого количества категорийных гостиниц (только две гостиницы в регионе прошли официальную оценку соответствия системе классификации гостиниц и других средств размещения).

3. В связи с этим, актуальным является привлечение крупных иностранных отельеров (Hilton, Rezidor SAS, Radisson SAS, Royal Hotel, Novotel, Accor и т. п.), которые через свои управленческие компании обеспечивают стабильный сервис и имеют четко разработанные и одинаковые во всех гостиницах мира внутренние стандарты. Также необходимо учитывать, что сами международные управляющие компании практически не вкладывают средства в развитие отельного бизнеса в России. Marriott, например, уже лет 8-10 принципиально не инвестирует в отельный бизнес ни в одном регионе мира, только продает франшизы и контракты на управление. Вот и в Иркутске уже более 5 лет работает отель Кортярд Марриотт по франшизе всемирно известной марки. В последние годы в России появились собственные национальные управляющие компании: «Амакс» (13 гостиниц в европейской части страны), Accord management group, «Интурист Хотел Групп» (созданный на базе ВАО «Интурист), «Алросо», «Русские отели», «Евразия», «Форстон» и другие, которые развивают бизнес с учетом российской специфики, местного законодательства, что является более эффективным.

4. Неравномерное распределение гостиниц по региону, основные средства размещения сосредоточены на территориях, прилегающих к оз. Байкал (г. Иркутск, Иркутский, Ольхонский, Слюдянский районы). В настоящий момент в Иркутской области насчитывается 137 гостиниц с номерным фондом порядка

\section{Baikal Research Journal}


6800 тыс. мест. В городе Иркутске находится 64 гостиницы, с номерным фондом порядка 4000 мест.

5. Невысокий профессиональный уровень работников этой сферы может стать весомой проблемой в формировании рынка качественных гостиничных услуг. Изза нехватки кадров на туристско-гостиничном рынке, сейчас руководители гостиниц буквально "охотятся» за грамотными выпускниками направления «Туризм». Уже ко 2-3 курсу обучения студенты получают шанс совмещать учебу и работу, причем, если 5-10 лет назад на вакансию администратора на ресепшн могли рассчитывать только выпускники, то теперь даже младшекурсники успешно осваивают эту должность.

Начиная с 2000 г. в г. Иркутске отмечается рост количества новых небольших гостиниц с малым номерным фондом $(47,6 \%)$. С 2005 г. на гостиничном рынке Иркутска появились мини-гостинцы (квартиры гостиничного типа). Рост номерного фонда составил в среднем $9,7 \%$ в год, в последние годы за счет появления гостиниц с малым количеством номеров.

В основном, большие гостиницы спроектированы с окончательным числом номеров, где не предполагается увеличение номерного фонда. $К$ большим отелям можно отнести гостиницы «Ангара», «Марриотт», «Иркутск», «Северное море».

Характерным признаком является отсутствие четкой категорийности номеров, каждое средство размещения применяет свои наименования для номерного фонда. В частности, встречаются следующее: апартаменты, стандрат, люкс, полулюкс, номера высшей категории, номера категории А и B, twin, президент - сюит и т. п.

Среднесписочная численность работников гостинично-ресторанной сферы в 2015 г. составила 23167 чел. В среднем, рост количества занятых за последние 5 лет составил 8,4 \% в год. За последние 2 года в связи с вводом новых гостиниц отмечается рост количества занятых в гостиничном бизнесе на $16-18 \%$ в год ${ }^{1}$.

Среднегодовая численность работников гостинично-ресторанной сферы в Иркутской области неуклонно растет, причем этот рост будет значительно более существенным в ближайшие годы из-за резкого увеличения количества объектов данной сферы и введения новых должностей.

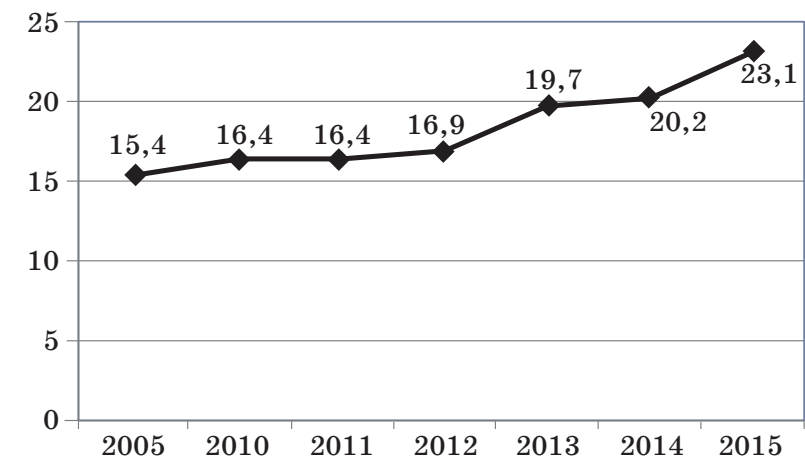

Рис. 1. Среднегодовая численность занятых в Иркутской области в гостинично-ресторанной сфере, тыс. чел.

Среднемесячная зарплата «гостиничников» в 2016 г. составила около 16619 р., в среднем за 5 лет рост заработной платы занятых в этом бизнесе составил порядка $12 \%$ в год, наибольший рост отмечается с 2013 г. в связи с вводом в эксплу-

${ }^{1}$ Регионы России. Социально-экономические показатели. 2016 : стат. сб. М. : Росстат, 2016. 1326 с.

\section{Baikal Research Journal}


атацию новых гостиниц. Сейчас уже для работников стойки ресепшн предлагают зарплату не менее 20 тыс. р. в месяц (рис. 2).

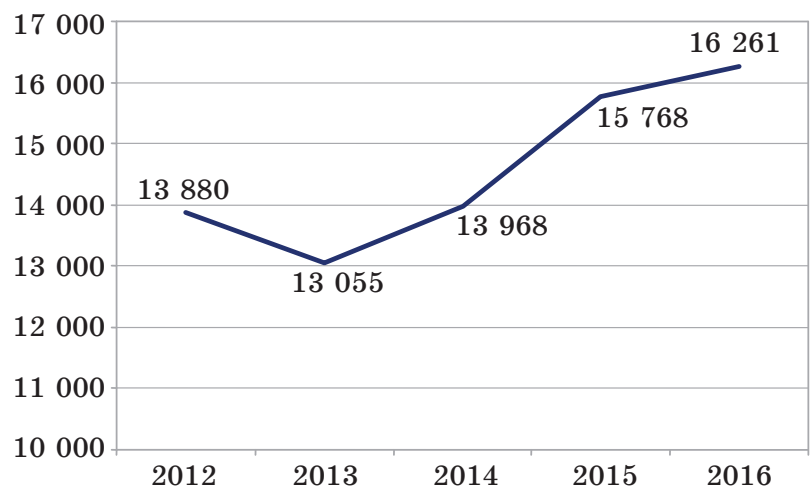

Рис. 2. Рост среднемесячной зарплаты

в гостиничной сфере Иркутской области, $p$.

Коэффициент загрузки иркутских средств размещения составляет порядка $55,8 \%$ в год. При этом отмечается то, что наибольший коэффициент загрузки (70-95\%) наблюдается у современных гостиниц, построенных после 2000 г. и малых гостиниц квартирного типа. У гостиниц старого образца коэффициент среднегодовой загрузки составляет не более 50 \%. Огромную роль в показателях загрузки играет сезонность, но благодаря большому количеству событийных мероприятий, активно внедряемых в жизнь Прибайкалья, эти показатели практически нивелировались. Такие отели как «Марриотт» и «БайкалБизнесЦентр» загружены практически круглый год полностью, ведь они постоянно подключены к процессу размещения участников крупных событий.

Согласно данным Агентства по туризму Иркутской области за последние годы произошел и рост количества ночевок, он составил 12,8 \% в год (рис. 3), т. е. сейчас гости останавливаются в нашем регионе не на 2-3 дня, а более чем на 6-7 дней. Это явное достижение можно отнести к успеху разработчиков более долгосрочных туристских программ и организаторам деловых мероприятий.

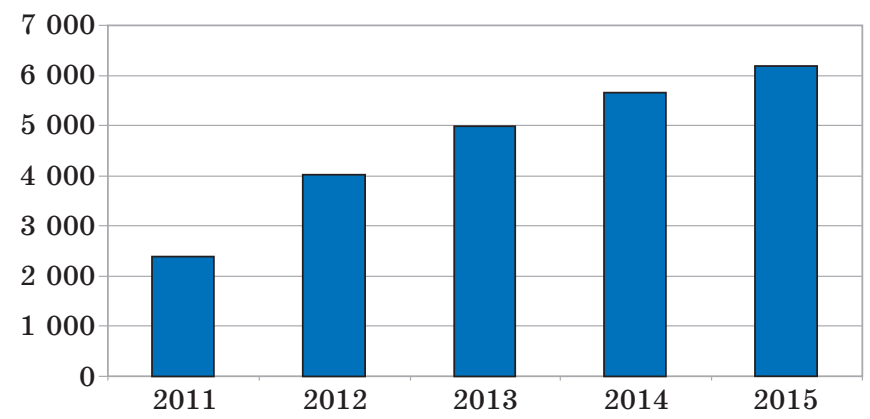

Рис. 3. Рост количества ночевок в гостиницах Иркутской области

Согласно прогнозам, к 2026 г. туристический поток в Иркутскую область существенно вырастет (рис. 4). Для азиатских стран российский туристский рынок очень привлекателен. На сегодняшний день ожидается увеличение потока из $\mathrm{Pe}-$ спублики Корея и Индии. Если изменится политическая ситуация, то возможен возврат туристского потока из Европы и Америки, причем с перевесом туристов из Германии и Скандинавии.

\section{Baikal Research Journal}


В настоящий момент самыми востребованными являются средства размещения эконом-класса, следовательно, они и являются самими многочисленными. Гостиницы, предоставляющие обслуживание VIP уровня либо изначально располагают количеством номеров до 50, либо выделяют отдельный этаж или сектор в гостиничном корпусе.

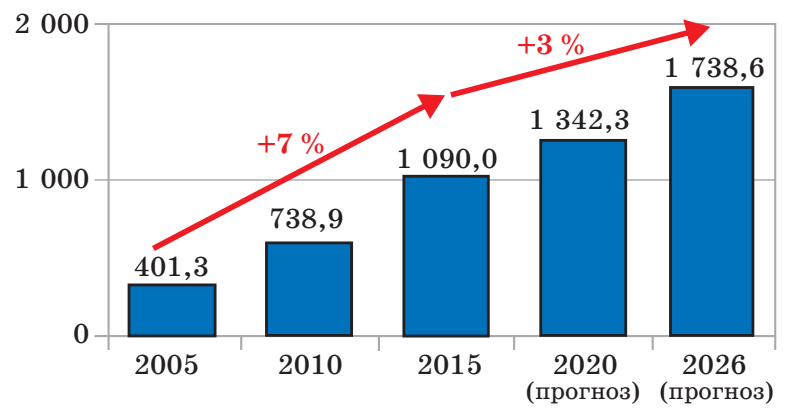

Рис. 4. Прогнозируемый поток туристских прибытий в Иркутскую область, тыс. чел.

Наибольшую долю среди туристов из РФ в 2026 г. будут занимать туристы, совершающие однодневные поездки (рис. 5).

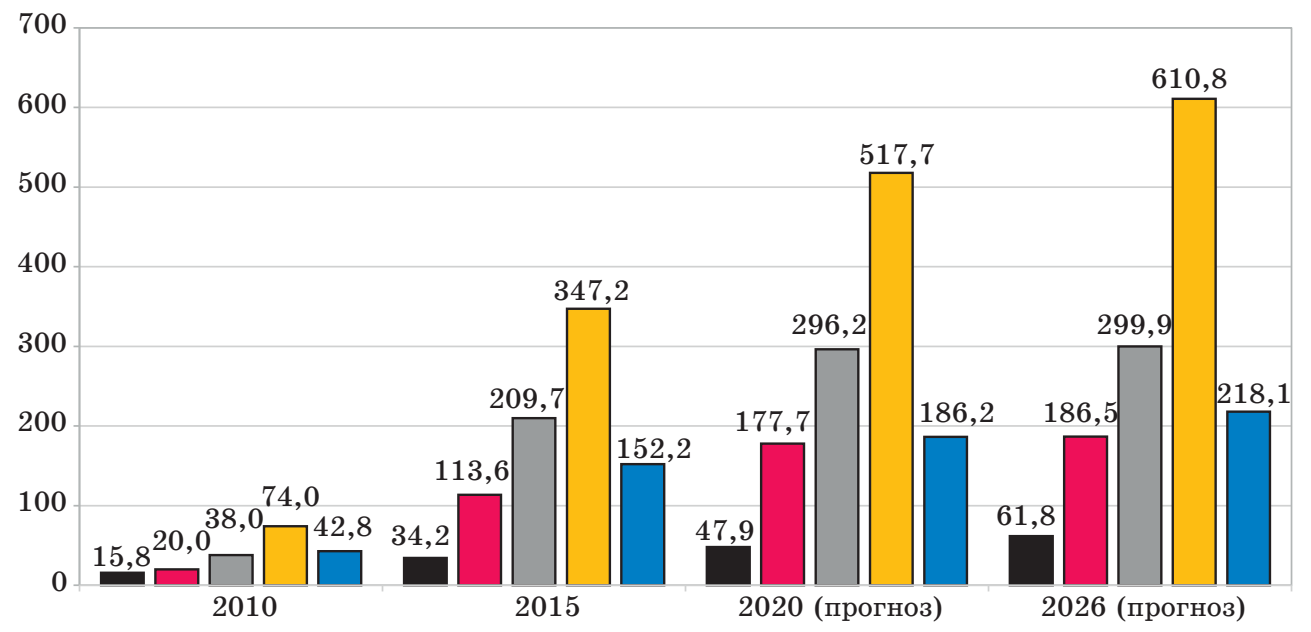

VIP класс $\square$ Средний класс $\square$ Эконом-класс $\square$ Без ночевок $\square$ Отдыхающих в котеджах

Рис. 5. Диналика прибытий туристов из России различных классов, тысс. чел.

Среди иностранных туристов наибольший долю в 2026 г. будут занимать туристы эконом-класса и предпочитающие отдых в коттеджах. В настоящее время только $15 \%$ средств размещения города Иркутска и области способны принимать туристов уровня VIP. Причем большая часть из этих средств размещения готова предоставить ограниченное количество номеров, соответствующее запросам туристов. Но фактически уже сейчас Иркутск приобретает статус одного из крупнейших коммуникационных центров России, пропускающего через себя потоки идей, информации, событий, людей, финансов и грузов. Одна из наиболее важных характеристик Иркутска заключается в том, что он расположен практически на пути главных коммуникаций со странами Востока.

\section{Baikal Research Journal}


Ожидаемые суточные расходы туристов в 2017 г. составят от 3 тыс. р. до 20 тыс. р., при этом наибольшую долю в расходах будут занимать расходы на проживание.

Сравнительный анализ уровня загрузки туристских гостиниц Иркутской области с 2008 по 2016 г. показал:

- летний высокий сезон с одного летнего месяца июля продолжается на август и сентябрь;

- ряд городских и пригородных гостиниц улучшил показатели на 15-20\% в межсезонье за счет проведения зимних программ приема и обслуживания туристов;

- отмечается высокая загрузка в зимний сезон гостиниц расположенных в местностях имеющих горнолыжные центры Байкальск и Листвянка;

- девальвация национальной валюты в 2014 г. сделал конкурентным отдых на Байкале для международных туристов, которые стали посещать Байкал практически круглогодично;

- открытие сетевого отеля Мариотт в 2011 г. также повлияло на рост туристского потока и повышение качества обслуживания туристов российских и иностранных;

- рост номерного фонда в Иркутской области за 2008-2016 гг. составил более 6000 номеров или около $30 \%$.

В результате маркетингового исследования выявлена тенденция неравномерной загрузки в течении недели между городскими отелями и пригородными. Если в городских отелях основной пик загрузки выпадает на рабочие дни и практически падает до минимума в выходные, то в загородных отелях картина обратная.

Программы обслуживания по выходным дням может значительно повысить уровень загрузки как городских, так и пригородных отелей при условии пакетных продаж при значительных скидках. Так как в несезон отдельные отели рекламируют скидки до 60-70\% .

Город Иркутск по данным поисковых систем Яндекс и информации онлайн тревел агентств (ОТА) входит в первую десятку по запросам в высокий летний и зимний сезоны, а также в дни российских событийных мероприятий.

Для крупных российских и зарубежных туроператоров еще с советских времен закрепилось название «транзитный город». Программы обслуживания транзитных туристов в международных программах увеличить достаточно сложно, но в этом тоже наметился положительный тренд.

Специализированные программы обслуживания российских туристов по тематике, включающей посещение города Иркутска и озера Байкал, пока сдерживаются отставанием развития базовой инфраструктуры, что дает возможности транспортной доступности только 8-12 туристских центров обслуживания в прибрежной и горной части Байкальской природной территории.

Почти 98 \% государственных земельных ресурсов в Байкальской природной территории не имеют первичных документов кадастровой регистрации, что выступает главным фактором, сдерживающим развитие программ обслуживания туристов на территории.

Традиционные программы обслуживания туристов сегодня опираются на 3-5 объектов показа: музей «Тальцы», Байкальский музей и городские музеи, в которых при увеличении туристского потока уже снижается качество обслуживания за счет того, что при формировании очереди, группы обслуживают непрофессиональные экскурсоводы, просто сопровождающие группы. Конечно практически все музеи уже объединились в своем нежелании пускать туристов в

\section{Baikal Research Journal}


сопровождении экскурсовода без соответствующих аккредитационных документов. Но, к сожалению, этот процесс еще не достаточно отработан при большом потоке гостей.

Рост номерного фонда вызван приходом на рынок новых субъектов российского туристского бизнеса, в том числе китайских и корейских туроператоров и владельцев средств размещения являющимися не резидентами России.

Наибольший рост загородного номерного фонда показал Ольхонский район, в котором большая часть номерного фонда принимает туристов в летний сезон, хотя сейчас уже сформирован перечень средств размещения круглогодичного функционирования.

В Слюдянском районе наблюдается высокая зимняя загрузки, напрямую связанная с горнолыжным сезоном. В летний период основная часть туристов представлена отдыхающими в турбазах и детских лагерях школьниками. Основной же поток, посещающий район, самостоятельно организует свой отдых и практически не приобретает услуги местных организаций.

Иркутский район, в отдельных поселениях, таких как Листвянка, Большое Голоустное имеет высокий поток организованных и самодеятельных туристов и превышает все показатели устойчивого развития туризма по плотности и потоку на 1 га местности. В течении 10 лет шло согласование генерального плана поселения Листвянка и из 228 га поселения свободными остались только автодороги.

Город Иркутск показывает более высокие показатели по загрузки отелей из-за активной деятельности Туристской информационной службы города и профессиональной деятельности управляющих команд туристских отелей. Также в городе отмечается значительный рост индивидуальных средств размещения типа апартамент, мини-отель и хостелы.

В документах стратегического планирования развития России и регионов на среднесрочную перспективу рекомендовано развитие городских агломераций, как городов «постиндустриального развития» и пригородных лесов в целях рекреации.

Как было отмечено ранее в Иркутской области сформировались 12 точек концентрации объектов инфраструктуры коллективного и индивидуального размещения. Данные точки концентрации могут стать «ядрами» туристских кластеров, в которых сосредоточено от 15 до 40 объектов инфраструктуры туризма общественного питания.

Развитие туристских кластеров рекомендовано Правительством России еще в 2007 г. Данное поручение Президента РФ и Правительства РФ на территории региона пока не выполнено. Проект развития ОЭЗ ТРТ «Ворота Байкала» не прошел стадию проектирования за 10 лет. Проект создания межрегионального туристского кластера «Байкальское созвездие» находится на уровне согласования регионального правительства и Ростуризма.

В целом дальнейшее развитие сферы гостеприимства в Иркутской области находится на стадии зависимости от факторов. Факторы следующие:

- отраслевая программа развития туризма в Иркутской области 2011-2016 гг. не финансировалась с 2012 г.;

- документы стратегического планирования развития отрасли не приняты;

- генеральная схема развития туризма Иркутской области не разработана;

- перспективные инвестиционные площадки для развития туристской инфраструктуры не сформированы и не внесены в Схему территориального планирования Иркутской области и муниципальных образований планирующих развитие туризма;

\section{Baikal Research Journal}


- отсутствие кадастровых паспортов у 98 \% государственных земель особо охраняемых природных территорий и земель лесного фонда остановили реализацию перспективных инвестиционных проектов туристской инфраструктуры в Иркутском и Ольхонских районах.

Данная проблематика была поставлена на повестку дня в 2008 г. Общественной палатой Иркутской области и в течении 9 лет вопрос данного фактора не решен.

Планируемый переход к инвестиционной стадии развития индустрии туризма без решения факторных земельных вопросов не возможен, кроме отдельных земельных участков в границах поселений и городов.

Существующая локализация размещения коллективных средств размещения приводит к выводам в отдельных муниципальных образованиях Иркутской области количество коллективных средств размещения превышает суммарную численность более 20 субъектов Российской Федерации и требует внедрения новых технологий управления развитие туристских территорий.

В мире в настоящее время управление развитие перспективных туристских территорий осуществляется на основании Концепции управления развитием туристских дестинаций.

Локализация объектов туристской инфраструктуры представлена в двадцати пяти муниципальных образованиях, в том числе больших и малых городах региона. Предпосылки для развития культурно-познавательного, сельского туризма, экологического туризма и активных форм отдыха и туризма имеют большинство муниципальных образований.

Проведенное исследование позволило предположить, что на развитие туристско-гостиничной сферы области помимо территориальных, природно-климатических, социально-экономических и институциональных условий оказывают воздействие и некие другие факторы, требующие дальнейшего изучения [14].

\section{Список использованной литературы}

1. Мажар Л. Ю. Территориальные туристско-рекреационные системы: теория и практика формирования / Л. Ю. Мажар // Теория и практика туризма / отв. ред. В. М. Котляков, В. И. Кружалин, Н. В. Шабалина. - М. : Кодекс, 2014. - С. 62-80.

2. Суходолов А. П. История, современное состояние и перспективы развития индустрии туризма (в мире, России и Иркутской области) / А. П. Суходолов // Иркутский историко-экономический ежегодник: 2011. - Иркутск : Изд-во БГУЭП, 2011. — С. 85-92.

3. Суходолов А. П. Общемировые тенденции в развитии туризма / А. П. Суходолов // Известия Иркутской государственной экономической академии. — 2004. — № 2 (39). C. 26-30.

4. Морозов М. А. Роль туризма в устойчивом социально-экономическом развитии регионов сибирского федерального округа / М. А. Морозов, Н. В. Рубцова // Региональная экономика: теория и практика. - 2016. - № 8 (431). — С. 187-198.

5. Евстропьева О. В. Развитие туристской системы на Байкальской природной территории / О. В. Евстропьева // География и природные ресурсы. — 2016. — № 5. C. 184-195.

6. Евстропьева О. В. Системный подход и объяснительные модели в туризме / О. В. Евстропьева // Вестник Национальной академии туризма. - 2015. - № 1 (33). - С. 6-11.

7. Удалых С. К. Иркутская область - перспективный туристский центр Байкальской территории / С. К. Удалых // Стратегия устойчивого развития регионов России : сб. материалов 22-й Всерос. науч.-практ. конф. / под общ. ред. С. С. Чернова. - Новосибирск : Центр развития науч. сотрудничества, 2014. - Вып. 22. - С. 123-128.

8. Туристская индустрия сибирского региона: SWOT-анализ развития туристского комплекса Иркутской области / А. И. Куликова, А. А. Ефименко, А. С. Сороковикова, А. С. Мельчукова // Актуальные проблемы гуманитарных и естественных наук. 2016. — № 1-3. - C. 77-79.

\section{Baikal Research Journal}

электронный научный журнал Байкальского государственного университета 
9. Карпова Г. А. Проблемы совершенствования управления туризмом на уровне региона / Г. А. Карпова, Л. Б.-ЖЖ. Максанова // Известия Санкт-Петербургского государственного экономического университета. - 2016. - № 4 (100). - С. 87-93.

10. Никольская Е. Ю. Современные проблемы и перспективы развития гостиничного бизнеса / Е. Ю. Никольская // Путь науки. - 2015. - Т. 1, № 11. - С. 65-67.

11. Алмосов С. М. Гостиничный бизнес / С. М. Алмосов. - М. : Лаб. кн., 2011. - 94 с.

12. Современные проблемы и тенденции развития рынка гостиничных услуг в РФ / С. В. Дусенко, В. В. Бритвина, С. Е. Седенков, Н. В. Швыгина, Лхагвасурэн Гундэгмаа // Научное обозрение. - 2016. - № 6. - С. 129-131.

13. Науразова Э. А. Важность эффективных инвестиций для регионов РФ. Рейтинг регионов, информация для бизнеса, отраслевых министерств, крупных кампаний / Э. А. Науразова, С. Р. Шамилев // История. Экономика. Геополитика. - 2016. - № 1. - С. 1-15.

14. Сысоева Н. М. Проблемы развития предпринимательства в прибрежной зоне Байкала / Н. М. Сысоева, О. В. Сысоева // География и природные ресурсы. — 2016. — № 5. C. $144-150$.

\section{References}

1. Mazhar L. Yu. Territorial tourism and recreational systems; theory and practice of formation. In Kotlyakov V. M., Kruzhalin V. I., Shabalina N. V. (eds). Teoriya i praktika turizma [Tourism Theory and Practice]. Moscow, Kodeks Publ., 2014, pp. 62-80. (In Russian).

2. Sukhodolov A. P. History, current state and prospects of developing tourism industry (in the world, Russia and Irkutsk Oblast). Irkutskii istoriko-ekonomicheskii ezhegodnik: 2011 [Irkutsk Historical and Economic Yearbook: 2011]. Irkutsk, Baikal State University of Economics and Law Publ., 2011, pp. 85-92. (In Russian).

3. Sukhodolov A. P. Worldwide trends of tourism development. Izvestiya Irkutskoi gosu darstvennoi ekonomicheskoi akademii = Bulletin of Irkutsk State Economics Academy, 2004, no. 2 (39), pp. 26-30. (In Russian).

4. Morozov M. A., Rubtsova N. V. Tourism role in sustainable socio-economic development of the regions of the Siberian Federal District. Regionalnaya ekonomika: teoriya $i$ praktika $=$ Regional Economy: Theory and Practice, 2016, no. 8 (431), pp. 187-198. (In Russian).

5. Evstropeva O. V. Development of tourism system on Baikal natural territory. Geografiya $i$ prirodnye resursy $=$ Geography and Natural Resources, 2016, no. 5, pp. 184-195. (In Russian).

6. Evstropeva O. V. Systems approach and explanatory models in tourism. Vestnik Natsional'noi akademii turizma = Bulletin of National Academy of Tourism, 2015, no. 1 (33), pp. 6-11. (In Russian).

7. Udalykh S. K. Irkutsk Oblast as a prospective tourism center of Baikal territory. In Chernov S. S. (ed.). Strategiya ustoichivogo razvitiya regionov Rossii. Materialy Vserossiiskoi 22-i nauchno-prakticheskoi konferentsii [Strategy of sustainable development of Russia's regions. Materials of 22-nd All-Russian Research Conference]. Novosibirsk, Centre for Development of Scientific Cooperation Publ., 2014, iss. 22, pp. 123-128. (In Russian).

8. Kulikova A. I., Yefimenko A. A., Sorokovikova A. S., Melchukova A. S. Tourism industry of the Siberian region: SWAT analysis of tourism complex in Irkutsk Oblast. Aktual'nye problemy gumanitarnykh i estestvennykh nauk = Actual Problems in Humanities and Natural Sciences, 2016, no. 1-3, pp. 77-79. (In Russian).

9. Karpova G. A., Maksanova L. B.-Zh. Problems of improving tourism management at regional level. Izvestiya Sankt-Peterburgskogo gosudarstvennogo ekonomicheskogo universiteta = Bulletin of Saint Petersburg State University of Economics, 2016, no. 4 (100), pp. 87-93. (In Russian).

10. Nikol'skaya E. Yu. Modern problems and prospects of hotel business development. Put' nauki $=$ The Way of Science, 2015, vol. 1, no. 11, pp. 65-67. (In Russian).

11. Almosov S. M. Gostinichnyi biznes [Hotel Business]. Moscow, Laboratoriya knigi Publ., 2011. $94 \mathrm{p}$.

12. Dusenko S. V., Britvina V. V., Sedenkov S. E., Shvygina N. V., Lkhagvasuren Gundegmaa. Current problems and trends of developing hotel service market in the Russian Federation. Nauchnoe obozrenie = Scientific Review, 2016, no. 6, pp. 129-131. (In Russian).

13. Naurazova E. A., Shamilev S. R. The importance of effective investment for regions of the Russian Federation. Rating of regions, information for business, industry ministries

\section{Baikal Research Journal}


and large campanies. Istoriya. Ekonomika. Geopolitika = History. Economics. Geopolitics, 2016, no. 1, pp. 1-15. (In Russian).

14. Sysoyeva N. M., Sysoyeva O. V. Problems of entrepreneurship development in the coastal zone of Baikal. Geografiya $i$ prirodnye resursy $=$ Geography and Natural Resources, 2016, no. 5, pp. 144-150. (In Russian).

\section{Информация об авторе}

Ржепка Элина Анатольевна - кандидат географических наук, доцент, заведующий кафедрой туризма и гостиничного бизнеса, Байкальский государственный университет, 664003, г. Иркутск, ул. Ленина, 11, e-mail: rjepka@yandex.ru.

\section{Author}

Elina A. Rzhepka - PhD in Geography, Associate Professor, Head of Chair of Tourism and Hotel Business, Baikal State University, 11 Lenin St., 664003, Irkutsk, Russian Federation; e-mail: rjepka@yandex.ru.

\section{Библиографическое описание статьи}

Ржепка Э. А. О развитии туристско-гостиничного бизнеса в Иркутской области / Э. А. Ржепка // Baikal Research Journal. - 2017. - T. 8, № 1. — DOI: 10.17150/24116262.2017.8(1).10.

\section{Reference to article}

Rzhepka E. A. On developing tourism and hotel business in Irkutsk Oblast. Baikal Research Journal, 2017, vol. 8, no. 1. DOI: 10.17150/2411-6262.2017.8(1).10. (In Russian).

\section{Baikal Research Journal}

